\title{
AMAR EN LA CORTE. AMOR Y MATRIMONIO EN LA SOCIEDAD ESTAMENTAL
}

\author{
Vicenç Beltran \\ (Universitat de Barcelona-Institut d'Estudis Catalans) \\ vicent.beltran@ub.edu
}

\section{RESUMEN}

Existe abundante investigación sobre la teoría del amor cortés pero poca sobre su relación con los usos sociales. Las obras literarias y los tratados para la educación de la aristocracia sugieren que era ampliamente aceptado como pauta para la relación entre los sexos dentro y fuera del matrimonio y el estudio biográfico de los procesos matrimoniales del primer marqués de Cenete y del primer duque de Huéscar ponen de manifiesto que era usado como instrumento del cortejo y podía producir enamoramientos reales y radicales que llevaban al matrimonio, incluso contra la voluntad del linaje y de los reyes.

PALABRAS CLAVE: Amor cortés; matrimonio; corte; aristocracia.

\section{LOVING IN THE COURT. LOVE AND MARRIAGE IN THE STAMENTAL SOCIETY}

\begin{abstract}
Ample research exists on the theory of courtly love but very little of it deals with the relation between the theory and social norms. Literary works and treatises on aristocratic education suggest that courtly love was widely accepted as a model on which to base the relationship between the sexes both from within marriage and from outside it. Biographical analysis of the marriage proceedings pertaining to the first marquis of Cenete and the first duke of Huéscar reveal that it was used as a contrivance of courtship and that it could result in real and progressive love relationships that ended in marriage, even to the point of transgressing the expectations of pedigree and royalty.
\end{abstract}

KEY WORDS: Courtly love; marriage; the court; aristocracy. 
Cuando se analiza la evolución de los estudios sobre el sentimiento amoroso desde El proceso de la civilización ${ }^{1}$, punto de inflexión para la evolución de la historia social europea, sorprende que el autor basara su análisis de los usos amorosos en la obra de Erasmo, cuyo «latín conversacional» escamoteaba la realidad de su tiempo bajo una engañosa apariencia de naturalidad; su ejemplo, sin embargo, ha influido notablemente en el desarrollo de la investigación ${ }^{2}$. Aplicando las teorías sociológicas (entonces en boga) sobre su origen y traduciendo mecánicamente la sumisión amorosa como una aplicación de los deberes vasalláticos a la señora feudal ${ }^{3}$, no percibió el poder que irradiaba su teoría para la formación de una ideología de las relaciones sociales o un ideal de distinción ${ }^{4}$ cuya difusión corrió paralela a la de las buenas maneras en que basó su interpretación genética de la cultura occidental. Su influencia ha sido grande y el llamado genéricamente «amor cortés» apenas se ha tenido en cuenta en los estudios sociales a partir de la novela sentimental inglesa del siglo XVIII.

Ciertamente, el tema es un auténtico campo de minas. No cabe duda de que las formalizaciones de las artes de amar son artificiosísimas y responden a menudo a una idealización sin contacto con la realidad; por su parte, los estudios literarios y del pensamiento ${ }^{5}$ han analizado hasta la náusea las teorías expresas en las preceptivas y su aplicación en los diversos géneros, escuelas o épocas, pero han ignorado su relación con los usos sociales. Sin embargo, el problema no se resuelve soslayándolo, y de hecho cuando se lo aborda en la sociedad del siglo XVIII se parte habitualmente de las elucubraciones sobre el sentimiento amoroso propias de la novela sentimental, heredera de las teorías del Medievo y del Renacimiento ${ }^{6}$.

En las páginas que siguen trataremos de fijar las propuestas de nuestra investigación, para la que nos apoyaremos en estos supuestos ${ }^{7}$ :

\footnotetext{
${ }^{1}$ Norbert Elias, El proceso de la civilización: investigaciones sociogenéticas y psicogenéticas (México: Fondo de Cultura Económica, 2015, edición electrónica), segunda parte, cap. II, \ 9.

${ }^{2}$ Valga como ejemplo el excelente trabajo de Isabel Morant, Discursos de la vida buena. Matrimonio, mujer y sexualidad en la literatura humanista (Madrid: Cátedra, 2002), ver especialmente 46 y siguientes, donde se apoya en la tradición erudita del Humanismo.

${ }^{3}$ La difusión de los ideales corteses se estudia en Elias, El proceso de la civilización, cap. tercero, III, parte I, 8 \ 35 y 37 (“Génesis social de los trovadores y de los modales cortesanos"). El estado de la cuestión de que parte para la comprensión de la poesía trovadoresca, basado en concepciones sociológicas propias de la primera mitad del siglo XX, está hoy totalmente superado.

${ }^{4}$ Pierre Bourdieu, La distinción. Criterio y bases sociales del gusto (Madrid: Taurus, 2006).

${ }^{5}$ Citaré solo el último y más ambicioso de estos trabajos, Irving Singer, La naturaleza del amor. 1. De Platón a Lutero. 2. Cortesano y romántico. 3. El mundo moderno (México: Siglo XXI Editores, 1992).

${ }^{6}$ Para no salirme de los estudios más asequibles, mencionaré el estudio de Isabel Morant y Mónica Bolufer, Amor, matrimonio y familia (Madrid: Síntesis, 2000), \ 3 y \4.1-4.2.

${ }^{7}$ Ante la proliferación monstruosa de la bibliografía, remitiré solo a Georges Duby, Le chevalier, la femme et le prêtre: le mariage dans la France féodale (París: France Loisirs, 1981), Jean Gaudemet, El matrimonio en Occidente (Madrid: Taurus, 1993). Para el caso español véanse $\mathrm{M}^{\mathrm{a}}$ Francisca Gámez Montalvo, Régimen jurídico de la mujer en la familia castellana medieval (Granada, Comares, 1988), Adeline Rucquoi, Aimer dans l'Espagne Médiévale. Plaisir licites et illicites (París: Les Belles Lettres, 2008) y Jesús M. ${ }^{a}$ Usunáriz, "Marriage and Love in Sixteenth- and Seventeenth-Century Spain", en Marriage in Europe. 1400-1800, ed. Silvana Seidel Menchi (Toronto-Buffalo-Londres: University of Toronto, 2016), 201-224, 201-207, y su "El matrimonio como ejercicio de libertad en la España del siglo de oro", en El matrimonio en Europa y
} 
1) El amor cortés como un ideal de relación amorosa libre

2) La falta de libertad de los contrayentes en la formalización del matrimonio según los usos sociales y las legislaciones laicas ${ }^{8}$

3) La ambigua y compleja posición de la iglesia al respecto?: a) el derecho de los contrayentes a la libertad de elección matrimonial, b) la exigencia de respetar los deseos paternos

4) Por último, pero no menos importante, la condena de la relación amorosa libre.

El análisis de la documentación sobre algunos procesos amorosos y matrimoniales nos permitirá aproximarnos a la compleja dinámica social creada por estos factores, cuyas diversas formas de articulación constituyen el fulcro sobre el que gira la historia social del amor y del matrimonio en la civilización occidental.

No voy a repetir ahora las posiciones de los trovadores, fundadores de esta concepción del sentimiento amoroso ${ }^{10}$, pero sí expondré un aspecto menos conocido: el intento, muy temprano, de conciliar amor y matrimonio, que ocupó ya a Matfre Ermengaut en el tercer cuarto del siglo XIII:

Per est'amor hom eichamen

ve a matremoni soven [...]

aquest'amors non es res als

mas afectios naturals

de se carnalment ajustar

per la natura consservar;

e no's pot far l'ajustamens

ses matremoni lialmens

entre las genz ni az onor $[. . .]^{11}$

Por este amor el hombre también llega a menudo al matrimonio (...) el amor no es sino deseo natural de ayuntamiento carnal para conservación de la especie y en sociedad no se puede llevar a término honradamente sin legítimo matrimonio] ${ }^{12}$.

No se puede decir con mayor claridad: la única forma socialmente admitida de llevar a término la relación amorosa entre un hombre y una mujer consiste en fundar una familia mediante el matrimonio, propósito, como sabemos, difícil de alcanzar. Este desajuste daba lugar a un caleidoscopio de comportamientos que configuran la historia social del amor en Occidente.

el mundo hispánico: siglos XVI y XVII, ed. Jesús M. ${ }^{a}$ Usunáriz e Ignacio Arellano (Madrid: Visor, 2005), 167186, ambos trabajos importantísimos por enfrentar la teoría jurídica con casos reales documentados.

${ }^{8}$ Usunáriz, "Marriage and Love", especialmente 206-207.

9 James A. Brundage, Law, Sex and Christian Society in Medieval Europe (Chicago-Londres: University of Chicago Press, 1987).

${ }^{10}$ Citaré solo dos estudios clásicos, René Nelli, L'érotique des troubadours (Toulouse: Édouard Privat, 1963) y Moshe Lazar, Amour courtois et "Fin'amors" dans la littérature du XIIè siècle (París: Klincksieck, 1964), aunque no todas sus propuestas sigan vigentes.

${ }^{11}$ Matfre Ermengaut, Le breviari d'amor, ed. Peter T. Ricketts (Leiden: Brill, 1976), vv. 32 644-32 662.

12 Traducción de V. Beltran 
Durante la Baja Edad Media, la situación no había cambiado en lo esencial y, aunque la complejidad de la teoría ${ }^{13}$ y de los usos socialmente aceptados se habían desarrollado notablemente, su análisis resulta más fácil de lo que se cree. El poeta Joan Berenguer de Masdovelles nos dejó un cancionero autógrafo con rúbricas de inestimable valor para reconstruir la práctica cortés de su tiempo: allí encontramos por ejemplo un poema amoroso dedicado a «Alianor de Cardona, muller del marquès d'Oristany», con peticiones teóricamente tan inequívocas como «soplic que vostre sia» ${ }^{14}$; podríamos pensar en el amor supuestamente adulterino que se ha propuesto para las teorías trovadorescas, pero sabemos que esta dama partió de Barcelona en una nave del Hospital para reunirse con su esposo el primero de abril de 1451 y esta circunstancia nos permite comprender que el objetivo real del poema no era otro que un epitalamio, una celebración del inminente matrimonio de la dama. Nada que ver por tanto con las «afectios naturals / de se carnalment ajustar» que describía Ermengaut. Según las rúbricas a varios de sus poemas sabemos que fueron escritos por encargo de otros enamorados que, incapaces de componerlos, solicitaban sus servicios ${ }^{15}$. El amor cortés se aplicaba por tanto a situaciones diversas y a veces complejas que desbordaban la satisfacción de los propios deseos, aunque este fue siempre un objetivo imposible de olvidar o subestimar.

En efecto, a fines del siglo XV seguía siendo posible vincular estos tres componentes: el amor, la satisfacción del deseo y hasta el matrimonio, como acreditan varios poemas de Jorge Manrique: un decir amoroso contiene en acróstico «Guiomar», el nombre de su esposa, y de otro nos dice la rúbrica que contiene en anagrama «el nombre de su esposa [también Guiomar] y los linajes de los cuatro costados de ella, que son Castañeda, Ayala, Silva, Meneses» ${ }^{16}$; no podemos desestimar la hipótesis de que en los poemas destinados a la esposa el vocabulario habitual del amor cortés estuviera al servicio de las ceremonias del cortejo o del matrimonio más que de la pasión. Distinto parece el caso de otra de sus composiciones cuya rúbrica nos explica que lo escribió "porque estando él durmiendo lo besó su amiga» ${ }^{17}$. Aunque la

13 Pedro Cátedra estudió el desarrollo de la teoría amorosa castellana del siglo XV y principios del XVI, notablemente imbricada en el pensamiento escolástico, en su Amor y pedagogía en la Edad Media (Salamanca: Universidad de Salamanca, 1989).

${ }^{14} \mathrm{El}$ poema, «A vos, qui sou de complida bellesa» fue publicado en Joan Berenguer de Masdovelles, Canconer dels Masdovelles (Manuscrit 11 de la Biblioteca de Catalunya), ed. Ramon Aramon i Serra (Barcelona: Institut d'Estudis Catalans-Biblioteca de Catalunya, 1938), n. ${ }^{\circ} 158$, con la rúbrica. Véase la reconstrucción de las circunstancias de su composición en Vicenç Beltran, "Copisti e canzonieri: I canzonieri di corte", Cultura Neolatina 63 (2003): 115-164, 148.

15 Véanse por ejemplo los números 100 y 104-106. Para estos aspectos, remito a Vicenç Beltran, "La disfressa de l'amor cortès: Joan Berenguer de Masdovelles i el seu cançoner”, Cancionero General 1 (2003): 9-28.

16 Véase Jorge Manrique, Poesía, ed. Vicenç Beltran (Madrid-Barcelona: Real Academia EspañolaGalaxia Gutenberg-Círculo de Lectores, 2013), poemas n. 5 y 11. Los textos catalanes y castellanos los adapto a la ortografía moderna en todos los aspectos que no alteren la configuración fonológica y fonética de la lengua original.

${ }^{17}$ Ibídem, n. ${ }^{\text {}} 10$. 
conclusión resulta, como veremos, exagerada ${ }^{18}$, parece como si el sueño del siglo XVIII, la armonización de los deseos de los amantes con los de su entorno y con los planes de sus familias, estuviera ya vigente entre las expectativas sociales desde la baja Edad Media.

A pesar de lo que puedan sugerir estos testimonios y nuestras concepciones actuales, las opiniones distaban de ser concordes o, por decirlo más claramente, en el período al que estos testimonios pertenecen, el matrimonio por amor, aunque existía, podía ser abiertamente desaconsejado, como lo fue a lo largo del Antiguo Régimen ${ }^{19}$. El poeta Juan Álvarez Gato respondió a una enamorada que le había propuesto matrimonio: «[...] no plega a Dios, / siendo mi señora vós, que os haga mi compañera»; no era una excusa formal si atendemos bien a sus argumentos:
amor verdadero
no quiere premia ni fuerça;
aunque me veré que muero,
nunca lo querré ni quiero
que por mi parte se tuerça.
Amarnos amos a dos
con una fe muy entera ${ }^{20}$

le parece mucho mejor partido.

El tema fue objeto de cuidadosa deliberación en una carta de Fernando del Pulgar a un destinatario desconocido ${ }^{21}$, con argumentos que parecen glosa al poema anterior con el que pudiera estar de alguna manera relacionado, y quién sabe si ambos textos remitían a algún caso real. Requerido su «parescer cerca del casamiento que se trata de vuestro sobrino», tras excusarse porque «si la cosa subcede bien, no es agradescido el consejo e, si acude mal, es reprehendido el consejero», comienza por preguntar

\footnotetext{
${ }^{18}$ Juan de Mata Carriazo, juzga que «[Gonzalo Fernández de] Oviedo registra como una manera especial y rara de llegar al matrimonio el casar por amores», véase "Amor y moralidad bajo los Reyes Católicos”, Revista de Archivos, Bibliotecas y Museos 60 (1954): 53-76, 67. Anota allí unos pocos casos de matrimonio por amor pero entre ellos no está el que vamos a estudiar, el cual sin embargo, aparece claramente especificado en la copia publicada por José Amador de los Ríos: «[...] casó por amores con doña María de Fonseca [...]» (Gonzalo Fernández de Oviedo, Batallas y quincuagenas, ed. Juan Pérez de Tudela y Bueso [Madrid: Real Academia de la Historia, 1983-2002], 1, 54). Es una pena que el deterioro del manuscrito haya vuelto inútil la copia transcrita por Juan Bautista Avalle Arce, que trataba por extenso del marqués, Batallas y quincuagenas (Salamanca: Diputación de Salamanca, 1989), 396-397.

${ }^{19}$ Véanse diversas opiniones de tratadistas del siglo XVI en Jesús M. ${ }^{a}$ Usunáriz, "Sentimientos e historia. La correspondencia amorosa en los siglos XVI-XVIII", en Cinco siglos de cartas. Historia y prácticas epistolares en las épocas moderna y contemporánea, ed. Antonio Castillo Gómez y Verónica Sierra Blas (Huelva: Universidad de Huelva, 2014), 251-274.

${ }^{20}$ Cito según Vicenç Beltran, Poesía española. 1. Edad Media: lírica y cancioneros (Madrid: Visor, 2009), n. ${ }^{\circ} 131$.

${ }^{21}$ Uso la edición de Paola Elia, Fernando del Pulgar, Letras (Pisa: Giardini, 1982), n. ${ }^{\circ}$ XXIV, 94-96.
} 
qué parecer puede ninguno dar en los casamientos, cuando en los amores que tenía el otro vuestro primo vimos el estudio que tenía en el traer y la vigilança en el servir, e qué temor avía de enojar y qué humildad en el rogar, qué deleite en el contemplar y qué diligencia en el visitar, qué alegría en el favor e qué tristeza en el disfavor, qué obediencia en el mandamiento y que alegría en ser mandado, qué devoción en el mirar e qué plazer en el amar, qué velar, qué madrugar, qué aventurar, qué posponer, qué sofrir, qué acometer

y así sigue exponiendo la sintomatología amorosa que tan bien conocemos por los poetas cortesanos.

Encarece esta devoción, pero lamenta que «de las cuales cosas, si sola una hiziese por amor de Dios como lo faze por amor de amiga, entiendo que en cuerpo y en ánima iría al paraíso»; y después de tan encomiástica introducción pasa a lamentar «cómo, después que alcançó por mujer la que adorava por señora, dentro de dos años hovo entre ellos tal discordia que buscava causa para haver divorcio della». Lo más interesante, sin embargo, es la conclusión que saca, enteramente concorde con la del poeta: «no nos maravillemos si quiriendo él amar como marido, fuese a ella grave ser tan presto subjecta de aquel que fue algún tiempo señora»; esta era exactamente la respuesta que Álvarez Gato había dado a su amante: «no plega a Dios, /siendo mi señora vós, / que os haga mi compañera».

Fernando del Pulgar sigue su carta relatando un nuevo caso relativo a la familia de su corresponsal: «vistes la fuerça y la manera que fue menester para traer el otro vuestro sobrino a que concluyese el casamiento que fizo y veemos agora cómo, dexado el aborrescimiento que primero tenía, poco a poco se le convertió en un amor tan ferviente e tan loco que se ha desnudado no sólo del poder y del entender, mas del querer y del saber, e está remitido a la mujer que primero aborrescía; la cual le tiene tan subjecto que le manda lo que quiere y como y cuando lo quiere, e le aparta cuando le paresce y le llama cuando le plaze e le defiende e le castiga y le quita lo que quiere e le da lo que le plaze; y el mancebo es ya venido en tan grand estremo de subjectión, que ni osa repugnar lo que le manda, ni dexa de hazer lo que ella quiere aunque él no lo quiera, e obedece el triste como servidor e sufre como siervo».

La condena de este matrimonio se basa, sin lugar a dudas, en considerar poco viril la actuación del nuevo marido, pues esta es su conclusión: «Destos dos estremos, éste diría yo, señor, que se deve huir por ser muy ajeno de todo varón y de toda razón e también porque haze poco en honra de la mujer tener marido que no vale nada». Visto lo cual se abstiene de dar un consejo claro y se conforma concluyendo que «pues la donzella es buena e fija de buena, concluidlo en ora buena».

Nótese que el argumento central no es baladí: el cortejo cortés presuponía la idealización de la dama y la total sumisión del enamorado, cuando en la vida real era la esposa quien había de estar totalmente sometida al marido, no solo según las leyes, sino también según la religión y la común opinión del tiempo. En estas circunstancias, el cambio de estado implicaba una inversión de sus relaciones y es lógico suponer que el resultado había de poner en grave aprieto a las dos partes; el resultado quedaba al albur del acoplamiento entre ambos caracteres, un ajuste esencial para la convivencia 
del matrimonio como advertía ya el viejo cuento del mancebo que casó con mujer brava que don Juan Manuel había incluido en su Libro de Patronio o del conde Lucanor ${ }^{22}$.

Nos hallamos seguramente ante un dilema en el que cada uno debía decidir según sus propias convicciones, sus experiencias y sus prejuicios. Juan Álvarez Gato era muy letrado, como Fernando del Pulgar, y no tiene nada de extraño que ambos se acogieran a los planteamientos de la sociedad erudita que, desde Aristóteles, pasando por Tomás de Aquino hasta los humanistas modernos no tenía (digámoslo amablemente) gran inclinación a creer en las bondades de la condición femenina. Juan Álvarez Gato, en cierto momento que no podemos precisar cronológicamente ${ }^{23}$, «aviendo conoscido el mundo [...] y visto que es todo condenación del ánima [...], deseando desnudarse de todas las vanidades, aficiones y lisonjas que ha seguido y malos exemplos que ha dado en los efetos de sus obras livianas, pensó de pelear con nuestros tres contrarios en cuyo poder se hallava [...] tomando nueva vida espiritual debaxo de la orden y ábito matrimonial y legal» ${ }^{24}$. No solo era letrado, sino que estuvo en muy buenas relaciones con el arzobispo Hernando de Talavera, por lo que, aunque en su vida cortesana se hubiese plegado a las convenciones poéticas habituales, como ponen de manifiesto sus composiciones amorosas y él mismo confesaba en la palinodia que he extractado, podemos considerarlo integrado en la doctrina de la Iglesia.

Desde la perspectiva cortesana no solo tenemos testimonios literarios, sino también algunas manifestaciones teóricas. No sabemos cuándo escribió Luis Milán El cortesano, ambientado en la corte del Duque de Calabria y Germana de Foix (muerta en 1536), pero publicado en $1561^{25}$; por otra parte, la obra, oscilando entre el tono facecioso y la seriedad de algunas propuestas, tampoco es de interpretación transparente: al lado de intervenciones aparentemente serias asistimos, por ejemplo, a un continuo bromear sobre las infidelidades de Juan Fernández de Heredia y a su aparentemente compleja vida matrimonial que parecen cuestionar la validez del conjunto.

No creo, sin embargo, que debamos minusvalorar el debate desarrollado en la «Jornada primera». En primer lugar, Baltasar Mercader condena el amor no correspondido, pues «poco ha que se provó con la vida de mi hermano don Berenguer Mercader, que murió de amores por una dama que se le casó, pensando que estava tan

22 Cito según don Juan Manuel, Obras completas, ed. José Manuel Blecua, 2 vols. (Madrid: Gredos, 1981-1983), II, cap. XXXV, 285-298.

${ }^{23}$ Francisco Márquez Villanueva ponía este texto en relación con una carta que él data en 1471 ¡Error! solo el documento principal.«a un amigo que se metió a fraile¡Error! solo el documento principal.», pero sus argumentos son demasiado conjeturales tanto para la datación como para su posible relación con la mentalidad del autor en sus Investigaciones sobre Juan Álvarez Gato. Contribución al conocimiento de la literatura castellana del siglo XV (2. ${ }^{a}$ ed., Madrid: Real Academia Española, 1974), 27-28; aunque esta carta contiene un elogio de la castidad (ibídem, 389), las convenciones adecuadas a cada género y momento podían imponerse sobre las convicciones del autor.

${ }^{24}$ Cito de nuevo por Beltran, Edad Media. Lírica y cancioneros, n. ${ }^{\circ} 133$.

${ }^{25}$ Ines Ravasini, "Poesía y vida de corte: los sonetos en El Cortesano de Luis Milán”, Revista de Poética Medieval 28 (2014): 335-357, https://doi.org/10.37536/RPM.2014.28.0.53210; analizando los sonetos que contiene la obra, los vincula a la corte valenciana y parece inclinarse por una datación temprana. 
casada en la voluntad de él como no lo fue, pues pudo casar con otro» ${ }^{26}$. Más adelante, con ocasión de una cacería cuyos avatares se aplican poéticamente a la relación amorosa, doña Ana, mujer de Miguel Fernández, afirma muy seriamente que «para conservarse la voluntad entre los casados siempre ha de saber a servidor el marido, porque no sea tenida en poco la mujer ${ }^{27}$ y Luis Vique afirma ante su esposa que «si antes de casar, cuando ella manda, se dexa mandar de la razón, después de casada no se puede desmandar para dar passión» ${ }^{28}$. Estas afirmaciones parecen indicar que no debía resultar socialmente bien visto que el marido usara o al menos abusara de sus prerrogativas legales, pero es mucho más claro el diálogo entre Pedro Mascó y su esposa Castellana de Belvís, que dice: «siendo casados siempre han de venir delante sus mujeres como servidores para ser buenos maridos, con mucho desseo, a bever de la fuente del desseo de su mujer, porque en perderse los desseos reinan los menosprecios» o, dicho de otra manera, la relación matrimonial se degrada si el marido pierde las buenas prácticas del cortejo. El duque de Calabria corona su intervención sentenciando: «cavalleros: sirvamos nuestras mujeres como amigos y ellas servirnos han como a mujeres» ${ }^{29}$. Vale decir que el duque interviene siempre ex cátedra, sentenciando las moralejas deducibles de los episodios festivos que tanto gustaban a Luis Milán; en este caso, a pesar de la ambigüedad del juego de palabras, parece proponer la equiparación de los roles masculino y femenino entre los esposos, cuando menos en el plano de sus expresiones verbales.

El componente jocoso inevitable en estos diálogos, concebidos como un ejemplo de conversación ingeniosa y amena, corre a cargo del malcasado Juan Fernández de Heredia, que inventa una facecia a propósito de los amores de Petrarca: «siendo canónigo de Padua, dispensava el Papa que casasse con doña Laura [...] y consentía que biviesse con sus rentas eclesiásticas si se casava [...] y él [...] respondió al papa: "No quiero trocar los plazeres de la amiga por los enojos de la mujer"»" ${ }^{30}$ La condena tradicional del matrimonio entre enamorados es en este caso motivo de parodia, pues el diálogo era completamente serio; el duque, como corresponde a su función social, sentencia siempre los debates y Fernández de Heredia y su mujer divierten a la corte con sus desavenencias, sean estas reales o puro teatro para divertir a los duques. La aristocracia valenciana del segundo cuarto del siglo XVI, si no nos engaña el espejo de Luis Milán, aceptaba con naturalidad modelos de convivencia marital muy próximos a los que la novela inglesa del siglo XVIII presenta como comunes en la alta sociedad coetánea. Vista pues la teoría, cabe preguntarse: ¿hasta qué punto habían penetrado estos ideales en la vida social? La respuesta ha de buscarse en los archivos y en las crónicas de sociedad.

El mejor ejemplo nos lo da la historia del valenciano de adopción Rodrigo Díaz de Vivar y Mendoza, hijo del gran cardenal Pedro González de Mendoza, marqués de

${ }^{26}$ Lluís del Milà, El cortesano, ed. Josep Lluís Escartí, Vicent Josep Escartí i Antoni Tordera, 2 vols. (València: Biblioteca Valenciana-Universitat-Ajuntament de València, 2001) I, 196.

27 Ibídem, 210.

${ }^{28}$ Ibídem, 234.

${ }^{29}$ Ibídem, 239.

${ }^{30}$ Ibídem, 230, 231. 
Cenete y señor de Denia, Ayora y Jávea ${ }^{31}$; su hija Mencía fue precisamente la segunda esposa del duque de Calabria. Viudo desde 1492 de Leonor de la Cerda, con unos treinta años, puso sus ojos en María de Fonseca, hija de Fernando de Fonseca, señor de Coca y Alaejos, el cual, con el apoyo de su linaje, pretendía casarla por razones patrimoniales con su sobrino Pedro Ruiz de Fonseca. Con la colaboración de su madre, María no solo aceptó el cortejo del marqués, sino que, en la madrugada del 30 de junio al 1 de julio de 1502, lo recibió en su casa con promesa de matrimonio escrita y firmada, en presencia de la madre y otros testigos ${ }^{32}$, aunque a causa de la oposición paterna mantuvieron secreto su compromiso.

El padre pretendió casarla según sus planes y ante la situación creada apeló a la Reina; esta en 1503 decidió encerrar al marqués de Cenete en Cabezón para trasladarlo después a Simancas y autorizó la celebración del matrimonio convenido por la familia; habiéndose negado su hija a secundarle, el padre la encerró junto a su madre y servidores en la fortaleza de Alaejos y las sometió a malos tratos, a torturas y al engaño de que «el marqués del Cenete había sido degollado» ${ }^{33}$, hasta que ella aceptó casarse con su primo en la madrugada del 20 al 21 de julio de 1504; sin embargo, durante la noche de bodas, conminó a su flamante novio a no acercarse a ella «porque le retorcería la cabeza como a un pollo» ${ }^{34}$. La joven, siempre en rebeldía, escribió al arzobispo Cisneros una misiva estremecedora pidiéndole que intercediera ante la reina: «no solamente el marqués, mi señor, es mi esposo, mas es mi marido [...] Por la passión de Dios, que como cosa que toca a la conciencia de V. I. mire en esto, y assí trabaje de remediallo: porque si yo dexé de decir esto a la Reyna, nuestra señora, fue porque no tenía licencia del marqués para ello» ${ }^{35}$.

Desde su prisión, el marqués no solo no se excusó, sino que acusó a la reina de fomentar la bigamia, hasta que, tras su muerte, fue liberado el 26 de noviembre de 1504. Entre protestas escritas de doña María, el rey Fernando la puso bajo custodia en diversas fortalezas hasta que el problema legal se resolviera y fue después llevada al monasterio de las Huelgas de Valladolid, de donde la sacó Rodrigo tras la muerte de

31 Su historia es muy conocida; para sus manifestaciones literarias véase Vicenç Beltran, "Del pliego de poesía (manuscrito) al pliego poético (impreso): las fuentes del Cancionero General', Incipit 25 (2006): 21-56, especialmente 27-30. Ahora partiré de la síntesis de Óscar Perea Rodríguez, Estudio biográfico sobre los poetas del "Cancionero general" (Madrid: Consejo Superior de Investigaciones Científicas, 2007), 63-74. Para fuentes anteriores, la mejor información es el resumen del memorial que dio Francisco Layna Serrano, Historia de Guadalajara y sus Mendozas en los siglos XV y XVI, 4 vols. (Madrid: Consejo Superior de Investigaciones Científicas, 1942-1943, reedición de Guadalajara: Aache, 1994), II, 245-247.

${ }^{32}$ La documentación se conserva publicada en el Memorial del pleito entre D. Íñgo López de Mendoza y Fonseca, marqués del Cenete, duque del Infantado, y D. Rodrigo Mesía y Fonseca, marqués de la Guardia, y D. Antonio de Toledo y Fonseca, Madrid, Real Academia de la Historia, Colección Salazar, V-60. Fue estudiado y dado a conocer por Juan Catalina García, "El segundo matrimonio del primer marqués de Cenete", en Homenaje a Menéndez Pelayo en el vigésimo año de su profesorado, ed. Juan Valera, 2 vols. (Madrid: Viuda e Hijos de M. Tello, 1899), II, 665-681.

${ }^{33}$ Catalina García, "El segundo matrimonio del primer marqués de Cenete", 673.

34 Catalina García, "El segundo matrimonio del primer marqués de Cenete", 675. Véanse casos muy parecidos de jóvenes bravías en J. M. ${ }^{a}$ Usunáriz, "El matrimonio como ejercicio de libertad", 174-175.

35 Catalina García, "El segundo matrimonio del primer marqués de Cenete", 680, nota 10. 
Felipe I (otoño de 1506) ${ }^{36}$. Óscar Perea ha podido localizar el documento de esponsales, que seguramente por la anomalía de su situación no se formalizó hasta el 9 de septiembre de $1514^{37}$. El rechazo de la familia de doña María y de la corte les obligó a retirarse a sus posesiones de Valencia, donde ella murió en 1521 y don Rodrigo, dos años más tarde.

Ante estas situaciones, suele resultar difícil o imposible dilucidar cuánto pudo haber de amor gratuito y cuánto de cálculo interesado; no parece este el caso: el marqués se ganó la malquerencia de los reyes y vivió retirado en Valencia, lejos de la corte y sus privilegios durante un período sumamente inseguro en el que los grandes apostaron fuerte para beneficiarse del desorden político; participó en la represión de la germanía, pero el protagonismo correspondió a su hermano que ocupaba el cargo de virrey. Pudo evitar la ruina por ser ya adulto y libre tras la muerte de su esposa Leonor de la Cerda, pero sobre todo porque, fallecido su padre en 1495, estaba en plena posesión de sus estados y rentas. Era, en suma, legal y económicamente independiente. Si el rapto de su esposa en lugar sagrado no acarreó mayores males hubo de agradecerlo a la crisis política que siguió tras las muertes consecutivas de la reina Isabel y de Felipe I; cuando al fin de las comunidades se restableció la estabilidad política, la monarquía no pudo ya revertir los hechos consumados, pero don Rodrigo nunca recuperó el favor de la corte. Algo semejante sucedió cuando la reforma protestante quebró en algunos lugares el poder del papado: ciertos magnates con suficiente influencia sobre las iglesias de nueva creación, como Enrique VIII o el Landgrave Felipe I de Hesse, impusieron su propio divorcio, aunque la legislación eclesiástica del matrimonio no resultó de momento gravemente alterada ni siquiera en los países protestantes.

Si atendemos ahora a la situación de su esposa, como mujer estaba sujeta a la tutela paterna; contó con la complicidad de su madre, que le pudo dar apoyo afectivo y encubrir su matrimonio secreto, pero ante los malos tratos paternos hubo de ceder; solo la osadía de don Rodrigo y las circunstancias políticas les permitieron reunirse. María se granjeó el rechazo de su familia y la condena de su padre, que la desheredó; el amor chocó con la oposición de su linaje, que tenía otros planes, y con los de la reina, cuyo apoyo había conseguido; a juzgar por la carta a Cisneros, parece que María esperaba algo de él, aunque su rechazado marido contaba con la colaboración de su tío y consejero de los reyes, el obispo Juan de Fonseca; la Iglesia, por tanto, permaneció neutral, quizá por lo enmarañado de la situación legal y política y por su eterna oscilación entre el respeto de los contrayentes a la decisión paterna y la defensa de su

\footnotetext{
36 Véase Perea Rodríguez, Estudio biográfico sobre los poetas del "Cancionero general”, 72. La información procede de Jerónimo Zurita, Historia del rey don Hernando el Católico: de las empresas y ligas de Italia, ed. Ángel Canellas López, Magdalenta Canellas Allos y Antonio J. López Gutiérrez, 5 vols. (Zaragoza: Diputación General de Aragón, 1989-1996), IV, libro 7, \9 9, según el cual habría pasado de Las Huelgas a la fortaleza de Arévalo, lo que resulta incoherente con lo arriba expuesto y dicho por él mismo en $\int 24$. Perea da como fecha del nuevo rapto el 25 de septiembre de 1506; lo que da a entender Zurita, a juzgar por el contexto, es sencillamente que había tenido lugar después de la muerte del rey, acaecida este mismo día.

37 Perea Rodríguez, Estudio biográfico sobre los poetas del "Cancionero general”, 73, nota 62.
} 
libertad de elección ${ }^{38}$.

En suma, ambos enamorados y, por fin, cónyuges, tras ímprobos sufrimientos y enormes riesgos pudieron disfrutar su compañía con grandes costes personales; si salieron indemnes de su arriesgada aventura fue gracias a las gravísimas crisis dinásticas, institucional y social con las que, para su fortuna, coincidieron. Lo que nos interesa ahora es la existencia en el Cancionero general de 1511 de un Romance hecho por Quirós, sobre los amores del Marqués de Zenete con la señora Fonseca, íncipit «Mi desventura cansada» ${ }^{39}$. Se trata de un texto divulgadísimo, pues fue incluido en nueve impresiones de esta colección escalonadas entre 1511 y $1573^{40}$; de ahí lo tomó el Cancionero de romances publicado por Martín Nucio ca. $1547^{41}$ que lo mantuvo en cinco de sus reimpresiones (Medina del Campo y Amberes ${ }^{42}$ en 1550, Amberes, 1555 y 1568 y Lisboa, 1581) y de allí pasó a su vez a la Primera parte dela Silua de varios romances que publicó en Zaragoza Esteban de Nájera en $1550^{43}$, de donde pasó a sus dos reediciones (Barcelona, 1550 y 1552). Tenían más divulgación los pliegos sueltos que, por su bajo precio, circulaban mucho más; sabemos que fue incluido en tres de origen burgalés: el $658^{44}$, publicado

\footnotetext{
${ }^{38}$ Aparte de la información aportada por Gaudemet, El matrimonio en Occidente, véanse diversos casos españoles en Usunáriz, "Sentimientos e historia", 237.

${ }^{39}$ Hernando del Castillo, Cancionero general (Valencia: Cristóbal Kofman, 1511), reproducción facsímil Antonio Rodríguez-Moñino (Madrid: Real Academia Española, 1958), f. 139r. Hay edición del cancionero por Joaquín González Cuenca, Cancionero general de Hernando del Castillo, 5 vols. (Madrid: Castalia, 2004), II, n. ${ }^{\circ} 455,563-565$. Cito por la edición que incluyo en el anexo, pero utilizo también la edición crítica del autor (con un estudio de la transmisión textual del romance de conclusiones diversas de las mías) en Quirós, Poesie, ed. Massimiliano Andreoli (Nápoles: Liguori Editore, 2005), n. ${ }^{\circ}$ 13. Este autor glosó el romance juglaresco «Rosa fresca, rosa fresca», donde la amada es defraudada con la mentira de que «érades casado, amigo, / allá en tierra de León» (ibídem, n. ㅇ 83, vv. 13-14). Dado que, estando presa María de Fonseca, la engañaron diciéndole que don Rodrigo había sido asesinado para que accediera a casarse con su primo, me pregunto si será una alusión; careciendo de todo dato sobre el poeta y sobre sus relaciones con el magnate, la propuesta resulta imposible de probar. Recuerda también nuestra historia la glosa de la canción «La que tengo no es prisión», pues su autor la escribió menospreciando la cárcel que sufría en Granada al compararla con la amorosa, y esta es también la situación en que se encontraba el marqués de Cenete. Aunque no tengamos una identificación suficientemente documentada del autor, debió estar al servicio del marqués.

${ }^{40}$ Uso Antonio Rodríguez-Moñino, Manual bibliográfico de cancioneros y romanceros del siglo XVI, coord. Arthur L.-F. Askins, 4 vols. (Madrid: Castalia, 1973), II, 586.

${ }^{41}$ Se puede consultar en Cancionero de romances impreso en Amberes sin año, con una introducción de Ramón Menéndez Pidal, ed. facsímil Ramón Menéndez Pidal (Madrid: Centro de Estudios Históricos, 1914 y Madrid: Consejo Superior de Investigaciones Científicas, 1945).

42 Reproducción facsimilar Cancionero de romances en que estan recopilados la mayor parte delos Romances Castellanos que fasta agora sean compuesto. Nueuamente corregido emendado y añadido en muchas partes. En Envers, En casa de Martin Nucio. M. D. L., ed. Paloma Díaz-Mas (México: Frente de Afirmación Hispanista, 2017). Tenemos además la transcripción del Cancionero de romances (Anvers, 1550), ed. Antonio RodríguezMoñino (Madrid: Castalia, 1967).

${ }^{43}$ Tenemos también edición facsimilar en Primera parte dela Silua de varios romances [...], ed. Vicenç Beltran (México: Frente de Afirmación Hispanista, 2016).

${ }^{44}$ Uso para su identificación Antonio Rodríguez-Moñino, Nuevo Diccionario bibliográfico de pliegos sueltos poéticos. Siglo XVI, ed. Arthur L.-F. Askins y Víctor Infantes (Madrid: Castalia-Editora Regional de Extremadura, 1997), S 970, cuyas noticias actualizaré siempre según Arthur L.-F. Askins y Víctor
} 
entre 1515 y 1519 , en otro muy semejante, el número 668, de ca. 1540 y en otro misceláneo, el 1007, de ca. $1520^{45}$. Del autor, Quirós, solo podemos decir con certeza que estaba muy familiarizado con el entorno literario valenciano ${ }^{46}$.

Desde Menéndez Pelayo se ha acusado a la poesía cortesana de abstracción y desapego de la realidad; sus juicios son sobradamente conocidos, por lo que me limitaré a esta lapidaria afirmación: «coplas fútiles, coplas de cancionero, versos de amor sin ningún género de pasión, devaneos tan insulsos que parecen imaginarios, conceptos sutiles y alambicados, agudezas de sarao palaciego tan pronto dichas como olvidadas, burlas y motejos que no sacan sangre: algo, en suma, que recrea agradablemente el oído sin dejar ninguna impresión en el alma» ${ }^{47}$. Desde luego, no estamos ante una manifestación excelsa de poesía metafísica, pero si la estudiamos desde este punto de vista no entenderemos por qué fue tan importante en la vida social de la época ni cómo pudo modelar los usos amorosos hasta nuestros días. No haré ahora un estudio literario del romance (que por su longitud transcribo en apéndice), sino que, a la luz de cuanto sabemos de la historia sentimental de nuestro autor, trataré de interpretarlo y de ilustrar su funcionalidad personal y social.

Procuraré sintetizar así el contenido, nada claro por la propia naturaleza de los recursos de la expresión cortés: el eclipse de su razón, el consecuente desarreglo sentimental y el peligro de muerte inducen al desventurado a cambiar conducta para calmar su tristeza y dolor (vv. 1-8). Para conseguirlo, (el amor, quizá) le hizo concebir esperanzas buscando en un desierto donde caminó hasta delirar (vv. 9-20). Manteniéndose solo con amor llegó a una fuente cuya agua escapaba de los sedientos (vv. 21-28); desconcertado, se apoyó en su razón y la preocupación le hizo dormirse (vv. 29-38). En sueños vio correr un agua amarga a quien la probaba (otra vez el amor o sus esperanzas) con la que cargó (de llanto) sus ojos y todas sus potencias (vv. 3948). El deseo, ignorante del daño, lo despertó y los males se intensificaron al ver la fuente en realidad seca (vv. 49-56). El corazón y los ojos (sentimiento y llanto) estragaron el cuerpo (su salud) cuando había perdido ya el alma (el amor es pecado); si desdichas son amores, su vida es buena muestra (vv. 57-64).

Infantes, Suplemento al "Nuevo diccionario bibliográfico de pliegos sueltos poéticos (siglo XVI)" de Antonio RodríguezMoñino, ed. Laura Puerto Moro (Vigo: Academia del Hispanismo, 2014), \ 658.

${ }^{45}$ Para la relación entre estos tres pliegos y el cancionero véase Beltran, "Del pliego de poesía (manuscrito)", con abundante información bibliográfica. Para las dataciones uso Mercedes Fernández Valladares, La imprenta en Burgos (1501-1600), 2 vols. (Madrid: Arco Libros, 2005), II, apartado 3 ("Relación de pliegos sueltos poéticos burgaleses...").

${ }^{46}$ Véase el estado de la cuestión en Perea Rodríguez, Estudio biográfico de los poetas del cancionero general, 68 nota 38. Hay edición de este autor en Quirós, Poesie, n. $^{\circ}$ 13, 94.

47 Marcelino Menéndez Pelayo, Antología de poetas líricos castellanos. Poesía de la Edad Media, 13 vols. (Madrid: Viuda de Hernando, 1890-1908), que cito por la reimpresión en Santander: Consejo Superior de Investigaciones Científicas, 1945, x, 209. El tema es ya viejo, citaré solo las consideraciones de Keith Whinnom, ("Towards the Interpretation and Appreciation of the Canciones of the Cancionero general of 1511", en Medieval and Renaissance Spanish Literature. Selected Essays, ed. Alan Deyermond, William F. Hunter y Joseph Snow [Exeter: University of Exeter Press-Journal of Hispanic Philology, 1994], 114132, especialmente 118, y la introducción a Beltran, Edad Media: lírica y cancioneros, 9, 10. 
Naturalmente nos hallamos ante la expresión alegórica de un amor destructivo, que no encuentra vías de satisfacción. Las descripciones habituales del amor cortés lo suponen esencialmente adulterino y las que se basan en estudios posteriores a mediados del siglo XX, carnal; con anterioridad se tendía a creerlo pura retórica, sin relación con sentimientos o experiencias reales; el problema está en que fue evolucionando según escuelas y épocas. Su condición adulterina se puede sostener solo para algunos casos de la lírica occitana en que así se especifica; el componente sensual está también explícito (sobre todo en el siglo XII) para la poesía occitana, pero no en las demás escuelas. Desde mediados del siglo XIII incluso en Occitania se afirma explícitamente la descarnalización del sentimiento, pero esta es segura en el resto de escuelas romances (siciliana, galaico-portuguesa, francesa) desde su mismo nacimiento. El dolce stil nuovo le dio una vuelta completa: el amor sería un sentimiento unidireccional y gratuito sin correspondencia posible, ni siquiera tácita o a distancia, y había de resultar gratificante por sí mismo, en cuanto mejoraba moralmente al enamorado; las demás escuelas bajomedievales (la francesa, la catalana, la portuguesa y la castellana son las más representativas) exageraron la parte negativa: la dama no podía satisfacer los deseos del amante porque perdería su virtud, por ende el amor se convertía en un sentimiento autodestructivo que solo podía conducir a la desesperación y a la muerte.

Esto es exactamente lo que dice el romance: el enamorado solo es capaz de alimentar una pasión autodestructiva; por tanto, un correlato subjetivo apropiado cabría situarlo antes del otoño de 1506, cuando el audaz don Rodrigo, cual nuevo Cid, liberó a su dama del monasterio de las Huelgas. La realidad pudiera ser distinta. Resulta bien sabido que el lenguaje de esta poesía es doblemente ambiguo: tiene que cubrir todas las situaciones posibles ante el amor y la amada (pues es casi siempre poesía masculina) con un vocabulario muy reducido y ha de ornarlo necesariamente mediante complejos juegos de repetición léxica y de transposición semántica, especialmente mediante equívocos y paradojas. Sin embargo, se conoce menos su aspecto más reductor: las actitudes que se consideran poéticas son la declaración amorosa y la lamentación; cantar la satisfacción del deseo (que era posible en provenzal, pero no ya en las demás escuelas trovadorescas) solo resulta factible en la sátira y la parodia, pero en la poesía seria se encuentran solo casos esporádicos, como la esparsa de Jorge Manrique arriba citada. El romance podía funcionar, por tanto, como una queja por la desdicha en los malos tiempos o como un encomio para amantes tan fieles que, perseverando, acabaron consiguiendo su deseo; después de la reunión de los enamorados, cantado en el palacio de don Rodrigo ante la pareja y sus invitados, se convertiría en una exaltación, en pura celebración.

Podemos volver ahora a un episodio de la jornada primera de El cortesano, dedicada al amor en el matrimonio. El anfitrión, el duque de Calabria, caza un jabalí y lo presenta a su esposa, Germana de Foix, con este requiebro: «Un muerto presenta a otro: que el amor mata y haze matadon». Naturalmente, los dos muertos son el Duque (por amor) y el jabalí (que ha sido cazado) y el amor mata (a los enamorados) y los convierte en matadores [de caza mayor] para exhibición de su habilidad y para obsequiar a su dama. Sigue el autor: 
La reina respondió al requiebro del duque con una risa, y dixo:

-A mí me dizen: Je vus entendo ben.

Y el duque respondió:

-Y a mí me nombran Sans mal pensier. Y porque es assí como digo, cualquier de la compañía que mate caça, preséntela a quien quisiere [...] pues no quiero hazer presente sino a quien no soy ausente, que es a la reina, mi señora.

El texto es totalmente equívoco, lo mismo que los motes en francés que los esposos intercambian; sin embargo, el mensaje en conjunto es perfectamente explícito: el duque solo ofrecerá regalos a su esposa para evitar ambigüedades y ella sabe perfectamente que su relación es leal ${ }^{48}$.

El abuso de la abstracción y el equívoco ha perjudicado gravemente la recepción de este tipo de poesía que se tiene, no sin razón, por exageradamente artificiosa; sin embargo, era precisamente este artificio, la complejidad semántica y la ambigüedad de su sentido, lo que permitía aplicarla a cualquier ocasión, y era este refinamiento lo que buscaba la sociedad cortés para dignificar tanto el trato social como la relación amorosa ${ }^{49}$. Joan Berenguer de Masdovelles usaba el lenguaje de la declaración de amor para agasajar a una gran dama con ocasión de su matrimonio y es lógico suponer que lo hizo en público, durante las fiestas de la celebración, y el duque de Calabria usa el lenguaje de la desdicha amorosa para enaltecer la estabilidad y solidez de su matrimonio. Hoy tenemos ya notables estudios sobre esta faceta y quizá el más interesante sea el de Trevor Dadson, tan buen conocedor de la realidad social de la poesía, sobre la poetización de la relación amorosa entre Diego de Silva y Mendoza, conde de Salinas, y Leonor Pimentel, dama de palacio ${ }^{50}$. Sobre el uso de este lenguaje como modelo de las relaciones cortesanas o, por mejor decir, en el cortejo cortesano ${ }^{51}$, se ha escrito ya bastante y aquí mismo hemos visto cómo funcionaba según Luis Milán, pero podríamos haber citado igualmente cualquier pasaje del Arte de galantería de Francisco de Portugal ${ }^{52}$.

48 Milà, El cortesano, 200. El párrafo es más complejo: el duque invita a todos los cazadores a presentar la caza a quienes quieran y no a él, a quien corresponde por su dignidad y por ser el anfitrión, para que nadie dé ocasión a equívocos respecto a quién es la dama de su corazón.

${ }^{49}$ Para formas de amar propias de sectores sociales mucho menos encumbrados, véase por ejemplo M. ${ }^{a}$ Luisa Candau Chacón, "El amor conyugal, el buen amor. Joan Estevan y sus 'Avisos de casados", Studia Historica. Historia Moderna 25 (2003): 311-349.

50 Trevor Dadson, "Introducción" a Diego de Silva y Mendoza, conde de Salinas, Obra completa. 1. Poesía desconocida, ed. Trevor Dadson (Madrid: Real Academia Española-Centro para la Edición de los Clásicos Españoles, 2016), 71-85, luego revisado y actualizado en su Diego de Silva y Mendoza. Poeta y politico en la corte de Felipe III (Granada, Universidad, 2011), cap. III.

51 Véase por ejemplo M. ${ }^{a}$ Carmen Marín Pina, "Las cartas de amor caballerescas como modelos epistolares", en La recepción del texto literario. (Coloquio franco-español. Jaca, abril de 1986), ed. Jean-Pierre Étienvre y Leonardo Romero (Zaragoza: Universidad de Zaragoza, 1988), 11-24 y su "De los géneros y diferencias de las cartas caballerescas", Páginas de sueños. Estudio sobre los libros de caballerías castellanos (Zaragoza: Institución Fernando el Católico, 2011), 169-218, 182-201.

${ }^{52}$ Francisco de Portugal, Arte de galantería, ed. José Adriano de Freitas Carvalho (Oporto: Centro Inter-Universitário de História da Espiritualidade, 2012). 
Sin embargo, es en la epistolografía amorosa donde lo podemos analizar con mayor rigor y el resultado no es baladí, pues es una de las manifestaciones pragmáticas de esta poesía: propició la creación y desarrollo de un código expresivo muy caro a la corte y muy apropiado para el cortejo pero, como hemos visto, altamente ambiguo; podía responder a una mera manifestación de cortesanía, un pasatiempo inocente para divertir y halagar a las damas, pero podía usarse también en la expresión de una pasión sincera y hasta avasalladora. Y de todos modos, fuera cual fuese el sentido que quería darle su emisor, podía ser interpretado de forma diversa y hasta muy distinta por su destinatario. $\mathrm{O}$, en el peor de los casos, por algún lector no deseado.

Citaré solo unos pasajes de la correspondencia dirigida a doña Magdalena de Guzmán por don Fadrique Álvarez de Toledo (entonces duque de Huéscar, pues aún vivía su padre, el llamado gran duque de Alba), cargados de pasión y, a la vez, de sentimientos de la más elevada cortesía:

No penséis que hago mucho en sacrificar mi contento y mi voluntad por lo que os toca, que pues lo uno y lo otro es vuestro, justo es que dispongáis de ello conforme a como más cumpliere a vuestro servicio. Y esto, señora doña Magdalena, no es encarescimiento ni magníficas palabras, sino la verdad pura, a Dios guarde, y pues la trato con vós tan llanamente, bien será que vós la tratéis conmigo en este particular y dispongáis de mí de la manera que más os conviniere sin tener respeto a mí ni a cosa de esta vida sino a vuestro contento, pues sabéis que este es el que yo pretendo y no otra cosa ${ }^{53}$.

Como buen enamorado no dudaba en rozar el ridículo:

al parque de Madrid daba muy particularmente de todas estas cosas y, a ratos, me quejaba de vós y a ratos de mí, de la misma manera que si lo tratara con un gran amigo y muy discreto y que me respondiera a todo lo que le decía y quedara tan satisfecho de haber comunicado mi alma con el viento como si lo hubiera hecho con un hombre ${ }^{54}$.

Sus sentimientos eran tan sinceros que llegaba a afirmarle: «es, señora mía, de manera lo que os quiero que esto no me consiente que trate con vós trato ilícito [...] En esto acabará vuestra merced de creer cuán diferentemente os quiero de lo que jamás hombre quiso» ${ }^{55}$. Estas expresiones no son ninguna novedad; en el segundo cuarto del siglo XIII, Guilhem de Montanhagol afirmaba que «amans non deu voler per nulh talent

\footnotetext{
53 Santiago Martínez Hernández, "Cartas de amor y el amor en cartas en tiempo de Felipe II. El epistolario inédito de don Fadrique de Toledo con doña Magdalena de Guzmán, ca. 1565-1566", Hispanic Research Journal 18, 4 (2017): 283-305, 302, carta n. . 4, https://doi.org/10.1080/14682737.201 7.1337873. Véase también su "El desafío de la Casa de Toledo: Felipe II y el proceso contra don Fadrique de Toledo, IV Duque de Alba (1566-185)", Mediterranea. Ricerche storiche 29 (2013): 473-512. 7.

${ }^{54}$ Martínez Hernández, "Cartas de amor y el amor en cartas en tiempo de Felipe II", 305, carta n.

${ }^{55}$ Martínez Hernández, ibídem, 302, carta n. 3.
} 
/ ren qu'a sidons tornes a desonransa» ${ }^{56}$.

Lo pertinente para su interpretación era el contexto pues esto no lo decía o escribía un galán de teatro o de novela, sino el heredero de una de las mayores casas de la monarquía a una mujer de carne y hueso, pero también con un alma donde animaban ilusiones, esperanzas y sentimientos. Podríamos tomarlas también por banales promesas de enamorado y así habría sido, aún dicho en prosa, si se hubiese quedado aquí, pero en esta última cita se intercaló este pasaje, desde luego nada discordante del contexto y revelador de un amor sincero y generoso (o de una pasión descontrolada e inconsciente):

[...] esto no me consiente que trate con vós trato ilícito pudiéndole tratar tan lícito como lo será siendo desposados. En esto acabará vuestra merced de creer cuán diferentemente os quiero de lo que jamás hombre quiso, pues porque vós no hagáis cosa que no os esté bien, vengo a hacer lo que, si mis padres saben, perderé por ello su gracia perpetuamente, pues [...] es verdad, cierto, que los quiero con la mayor ternura que nunca hijo quiso a sus padres [...] pero todo esto me importa poco y todo cuanto hay en el mundo ${ }^{57}$.

El colofón formal de tanto deseo era la promesa más obvia: «os doy mi fe y palabra como caballero de me casar con vós» ${ }^{58}$. Esta promesa tenía consecuencias jurídicas muy graves y fue aquí donde el duque de Huéscar se perdió.

Al estallar el escándalo, ni el duque ni el rey estaban de acuerdo con este enlace hipergámico y trataron de cortarlo: les prohibieron casarse sin permiso y encarcelaron a la dama y al fogoso enamorado, que era ya treintañero y dos veces viudo; la cárcel le fue luego permutada por un destierro de seis años, tres sirviendo con diez lanzas a su costa en la plaza de Orán, nuevamente conmutado por el servicio en Flandes junto a su padre, que había asumido aquel gobierno; durante su ausencia, el duque concertó el matrimonio del heredero (a quien parecen habérsele enfriado ya los sentimientos) con su sobrina María Álvarez de Toledo Osorio. Cuando la corona, ante la reclamación de doña Magdalena y la presentación de estas cartas, decidió que el duque de Huéscar debía casarse con ella, este consumó el matrimonio concertado por la familia y provocó la cólera real (1578): le valió un destierro de doce años y la pérdida de sus cargos. Aquellas vehementes (y quizá poco meditadas) promesas de amor arruinaron a la vez su carrera, el prestigio de su padre y la posición política y social de su linaje.

\footnotetext{
56 «El enamorado no puede bajo ningún concepto pedir a su dama / nada que atente contra su honor», en «Nulhs hom no val ni deu esser prezatz», en Peter T. Ricketts, Les poésies de Guilhem de Montanbagol, troubadour provençal du XIIIe siècle (Toronto: Pontifical Institute of Mediaeval Studies, 1964) que puede consultarse en línea en Vicenç Beltran y Tomàs Martínez Romero, dirs., Corpus des Troubadours, https://trobadors.iec.cat/veure davantal.asp?id obra=1107 [fecha de consulta: 5/5/2019]. 3.

${ }^{57}$ Martínez Hernández, "Cartas de amor y el amor en cartas en tiempo de Felipe II", 302, carta n.

${ }^{58}$ Martínez Hernández, ibídem, 301, carta n. ${ }^{\circ}$.
} 
Los dos casos son muy distintos, pero en ambos subyace un mismo esquema: los enamorados anteponen la ética del amor cortés a los códigos que regían el matrimonio, el social-legal y el canónico que, aún manteniendo puntos de fricción, habían encontrado un amplio margen de compromiso. El amor nace de una inclinación instintiva, pero esta se desarrolla de modo distinto según las pautas culturales vigentes en cada sociedad; en la europea, desde el siglo XII, convivieron varios códigos: desde la renuncia a la relación erótica fuera del matrimonio exigida por la Iglesia hasta la satisfacción más o menos completa del deseo que permitía el código cortés, uno de cuyos principios era el valor absoluto de sus normas, superiores a todas las demás; su cumplimiento, como decían los escritores, ponía a los enamorados en otra dimensión donde las reglas sociales ordinarias ya no regían. Aunque pueda parecer extraño, pues no eran ya unos adolescentes inexpertos, tanto el marqués de Cenete como el duque de Huéscar escogieron este camino y se estrellaron contra todas las instituciones.

El duque de Huéscar tuvo mucha menos suerte que el marqués de Cenete: el rey estaba decidido a controlar los matrimonios de los grandes linajes, secular prerrogativa de la monarquía, la doctrina católica condenaba el caso como bigamia y había un jefe del linaje que actuó contra los deseos de su hijo (que la Iglesia mandaba respetar y reconocía el rey) imponiendo el matrimonio más conveniente a sus intereses. La Iglesia, el linaje y la ley sostenían puntos de vista distintos que confluyeron contra los deseos de los enamorados y destrozaron sus vidas. El caso no era atípico: sucedió lo mismo a Gastón de Francia cuando casó sin permiso del rey con Margarita de Lorena $^{59}$, o cuando lo hizo un sobrino del poeta Garcilaso de la Vega ${ }^{60}$. Fue la misma reacción de Enrique VIII cuando su sobrina Margaret Douglas casó en secreto con Thomas Howard en 1536, al parecer bajo la protección de Ana Bolena, pero sin la autorización del monarca; tras la ejecución de la reina y las graves acusaciones de que fue objeto, Margaret quedó demasiado cerca de la línea sucesoria y tanto ella como Howard fueron encarcelados en la Torre de Londres, donde nuestro hombre murió ${ }^{61}$; una relación que dejó también una bella correspondencia.

Según en qué contexto, la interpretación de las palabras de amor variaba completamente y las cañas de justar con damas se podían volver lanzas enarboladas por el rey, la Iglesia o la familia. El amor podía ser muy retórico y su misma retórica podía volverlo del todo carnal, dependía del ardor de quienes la proferían y del extremo a que hubiera llegado la relación: el contexto la podía resemantizar de raíz, pero, salvo excepciones poco frecuentes, que pudiera llegar hasta la sacristía no dependía de los enamorados, sino del rey, de la Iglesia y de la familia. La retórica podía llegar a ser tan importante y arruinar los linajes porque las palabras comunican y suscitan sentimientos y estos pueden derivar en pasiones; la palabra de los poetas había creado convicciones, éstas favorecían determinados afectos y de ahí resultaba una concepción del amor ajena a los principios vigentes según la familia, la monarquía y la iglesia. A medida que nos

\footnotetext{
${ }^{59} \mathrm{El}$ caso fue analizado por Gaudemet, El matrimonio en Occidente, 366.

${ }^{60}$ M. ${ }^{a}$ Carmen Vaquero Serrano, Garcilaso, príncipe de poetas. Una biografia (Madrid: Marcial Pons, 2013), 406-409.

${ }^{61}$ Kenneth Muir, "Unpublished Poems in the Devonshire Ms.", Proceedings of the Leeds Philosophical Society (Literary and Historical Section) 6 (1947): 253-82, 254-55.
} 
alejamos de la época de los trovadores, estos sentimientos se manifiestan más vehementes, más apremiantes. Medio siglo antes de los hechos que describimos había sido compuesta y publicada la novela de Juan de Flores, Grisel y mirabella; Lillian van der Walde considera que allí se muestra «una sociedad cuyos valores con respecto a la sexualidad no valen realmente para los individuos», que «la ley [...] se alza como un poder coercitivo que impide las decisiones individuales ajenas a lo que socialmente se norma» y que «el sistema social no convence a los miembros que lo conforman ni logra regir sus comportamientos individuales» ${ }^{62}$. Por su parte, Pedro Vélez de Guevara hizo que Pedro I de Portugal justificara por sus afectos su desapego ante la prometida oficial, la princesa Blanca de Navarra:
Muerta mi esposa, trató casarme otra vez mi padre con vuestra Alteza, señora [...] sin que este segundo intento conmigo comunicase; yerro que es fuerça que ahora vuestro decoro le pague ${ }^{63}$.

La forma en que los sentimientos influyen en la construcción afectiva de las sociedades del pasado comienza a ser hoy objeto de estudio a partir de la sociología y la psicología cognitiva, aunque los procesos involucrados permanecen aún oscuros y necesitan una buena exploración de campo ${ }^{64}$; por otra parte, los estudios recientes sobre los modelos de la relación epistolar amorosa en el mundo real, no ya de las clases altas, sino de círculos mucho más amplios y hasta populares, subrayan su origen literario y cómo la literatura, desde al menos el siglo XVI, creó «una cultura compartida de cómo debía expresarse el sentimiento amoroso» y «una determinada cultura del sentimiento, con una retórica, compartida en buena parte de la Europa Occidental, tanto por hombres como por mujeres» ${ }^{65}$; una cultura en la que una buena parte pudo deberse a la correspondencia incluida en las novelas ${ }^{66}$ pues, aunque fingidas y escritas por varones, las «cartas femeninas [allí insertas] descubren la relación de la mujer con la cultura escrita y confirman, en el terreno de la ficción, la realidad sobre la que se sustentan los ataques de los moralistas y autores graves hacia las mujeres que ocupan

${ }^{62}$ Lillian van der Walde Moheno, Amor e ilegalidad. "Grisel y Mirabella" de Juan de Flores (México: Universidad Autónoma Nacional de México-El Colegio de México, 1996), 98, 106, 107.

${ }^{63}$ Luis Vélez de Guevara, Reinar después de morir, ed. Giuseppe Carlo Rossi (Nápoles: Pironte e Figli, 1961), jornada I, vv. 471-478.

${ }^{64}$ Damian Boquet y Piroska Nagy, "Pour une histoire des émotions. L'historien face aux questions contemporaines", en Le sujet des émotions au Moyen Âge, ed. Piroska Nagy et Damien Boquet (París: Beauchesne, 2008): 15-51, 26-35.

${ }^{65}$ Jesús M. ${ }^{a}$ Usunáriz, "Palabras de amor en el mundo hispánico: emociones y sentimientos en la correspondencia privada del siglo de oro", en Por seso e por maestría. Homenaje a la profesora Carmen Saralegui, ed. Concepción Martínez Pasamar y Cristina Tabernero Sala (Pamplona: Eunsa, 2012), 555-597, 568, 571.

66 Véanse los casos aportados por Usunáriz, "Palabras de amor en el mundo hispánico", 241-246. 
su tiempo en devaneos amorosos, en la escritura y recepción de cartas» ${ }^{67}$.

El largo consenso social en cuanto a una forma determinada de expresar e interpretar los sentimientos y su función en la estructuración de la sociedad permiten explicar la fragilidad de la institución matrimonial en la Europa del Antiguo Régimen pese a la solidez del aparato institucional e ideológico que la amparaba, pues chocaba frontalmente contra convicciones sociales muy extendidas y profundas en las capas altas de la sociedad; y no hablamos de adolescentes, sino de hombres maduros que habían pasado ya previamente por el altar y de jóvenes ansiosas de libertad: «Armed with this language -which is to say, with self-awareness- young women formed by the cultural climate of early modern Spain, claimed independence and ventured out autonomously onto life's paths», y esto no solo sucedía en las clases altas ${ }^{68}$. No ha de sorprendernos tanto que en un par de siglos estas ideas derribaran los muros del estado, de la sociedad y de la religión; un proceso que no se inició a fines del siglo XVII o principios del XVIII como pretenden algunos estudiosos ${ }^{69}$, sino que se consumó entonces gracias a los cambios revolucionarios que debilitaron y acabaron por arruinar la estructura social, jurídica, religiosa y política en que el matrimonio se insertaba. Durante los dos siglos anteriores, al estudiar los procesos por matrimonio señala J. M. ${ }^{a}$ Usunáriz que

se estaba resquebrajando el principio de autoridad paterna y los tribunales debían responder con una búsqueda del equilibrio para resolver contradicciones, aparentemente inconciliables, entre la reivindicación de la autoridad de los padres y el libre arbitrio de los hijos, que podían poner en peligro la armonía social ${ }^{70}$.

En estos siglos se habían vivido intensos y numerosos episodios de conflicto cuyos resultados solo llegaron a ser positivos para la libertad personal cuando concurrían circunstancias muy favorables, aumentando así los puntos de fricción y el desgaste de la normativa matrimonial; su caída requería una coyuntura propicia y esta, aunque asomó durante la Reforma, no alcanzó todavía el peso que habría de lograr con la secularización y la racionalización de la cultura, las instituciones y el estado que siguió a las guerras de religión.

${ }^{67}$ Marín Pina, "De los géneros y diferencias de las cartas caballerescas", 195.

${ }^{68}$ Usunáriz, "Marriage and Love", 213.

${ }^{69}$ Michael Anderson, Approaches to the History of the Western Family. 1500-1914 (Londres: Macmillan, 1980), 48, donde recoge las conclusiones de las investigaciones anteriores.

${ }^{70}$ Usunáriz, "El matrimonio como ejercicio de libertad", 177. 
Romance hecho por Quirós sobre los amores del marqués de Zenete con la señora Fonseca (Cancionero general, $\mathrm{f}$. $139 \mathrm{r})^{71}$.

Mi desventura, cansada de los males que hazía, quísome mudar la suerte por ver si se mudaría la tristeza y el dolor que jamás se me partía por causa de la razón que a mi muerte se escondía. Ordenóme un pensamiento de plazer y de alegría que me quitó mis pesares, y diome la fantasía que, si remedio buscasse, ventura me le daría si supiesse conoscella, que no se me negaría; y metióme en un desierto muy solo, sin compañía, adonde caminé tanto que de mí ya no sabía. Havía tiempo passado que de amor me mantenía, enderescé mi camino a un poblado que ende había do hallé una fuente seca, porque el agua que tenía a quien más la desseava se le desaparescía.

$\mathrm{Yo}^{72}$, de sed y de desseo el alma se me sallía, si la esperasse o me fuesse qué hazer no me sabía.
Vi que jamás pensamiento de allá no se me partía, reposé sobre razón, pues mudar no me podía, y adurmióme allí el cuidado que desvelado me havía. Y assí, de verme durmiendo, vi ell agua cómo corría, muy dulce para miralla y amarga a quien la cogía, mas de ver mi gloria en ella de ningún temor temía y allí cargué yo mis ojos hasta que más no podía y el coraçón y memoria hasta que más no cabía. Mi voluntad ${ }^{73}$ ya contenta (por que el daño no sabía) díxome, "Señor, despierta, despierta, que es ya de día"; y después que fui despierto mayores males sentía, que hallé la fuente seca, más seca que no solía; mis ojos gastan ${ }^{74}$ lo suyo, el coraçón se lo envía y los dos gastan ${ }^{75}$ el cuerpo, que el alma no la tenía, que allí se quedó ahogada porque assí lo merescía. Si desdichas son amores, júzguesse en la vida mía.

${ }^{71}$ Modernizo la ortografía excepto las labiales, las sibilantes y la forma del artículo «ell». Resuelvo las abreviaturas sin indicarlo. Para la transmisión textual véase Beltran, "Del pliego de poesía (manuscrito)".

72 Quizá ha de entenderse 'ya' (así corrige González Cuenca), aunque hace sentido si lo entendemos como sujeto de «sabía».

73 'Deseo', en Tentative Dictionary of Medieval Spanish (second edition, greatly expanded, ed. Lloyd A. Kasten y Florian Cody (Nueva York: Hispanic Seminary of Medieval Studies, 2001), s. $v$.

74 'Deterioran', quizá mejor 'consumen' (Real Academia Española y Asociación de Academias de la Lengua Española, Diccionario de la lengua española, https://dle.rae.es/ [fecha de consulta: 5/5/2019], s. v.)

75 'Destruyen' (ibídem, s. v.). 


\section{REFERENCIAS BIBLIOGRÁFICAS}

Anderson, Michael, Approaches to the History of the Western Family. 1500-1914 (Londres: Macmillan, 1980).

Askins, Arthur L.-F., y Víctor Infantes, Suplemento al "Nuevo Diccionario bibliográfico de pliegos sueltos poéticos (siglo XVI)" de Antonio Rodríguez-Moñino, ed. Laura Puerto Moro (Vigo: Academia del Hispanismo, 2014).

Beltran, Vicenç, "Copisti e canzonieri: I canzonieri di corte”, Cultura Neolatina 63 (2003): 115-164.

—, "La disfressa de l'amor cortès: Joan Berenguer de Masdovelles i el seu cançoner", Cancionero General 1 (2003): 9-28, https://ruc.udc.es/dspace/handle/2183/26 $\underline{37 / \text { recent-submissions }}$

-, "Del pliego de poesía (manuscrito) al pliego poético (impreso): las fuentes del Cancionero General', Incipit 25 (2006): 21-56, http://www.iibicrit-conicet.gov.ar Lojs/index.php/incipit/issue/view/18/showToc

—, ed., Poesía española. 1. Edad Media: lírica y cancioneros (Madrid: Visor, 2009).

—, y Tomàs Martínez Romero, dirs., Corpus des Troubadours, https://trobadors.iec.cat [fecha de consulta: 5/5/2019].

Boquet, Damian, y Piroska Nagy, "Pour une histoire des émotions. L'historien face aux questions contemporaines", en Le sujet des émotions au Moyen Âge, ed. Piroska Nagy y Damien Boquet (París: Beauchesne, 2008), 15-51.

Bourdieu, Pierre, La distinción. Criterio y bases sociales del gusto (Madrid: Taurus, 2006).

Brundage, James A., Law, Sex and Christian Society in Medieval Europe (Chicago-Londres: University of Chicago Press, 1987).

Cancionero de romances (Anvers, 1550), ed. Antonio Rodríguez-Moñino (Madrid: Castalia, 1967).

Cancionero de romances en que estan recopilados la mayor parte delos Romances Castellanos que fasta agora sean compuesto. Nueuamente corregido emendado y añadido en muchas partes. En Envers, En casa de Martin Nucio. M. D. L., ed. Paloma Díaz-Mas (México: Frente de Afirmación Hispanista, 2017).

Cancionero de romances impreso en Amberes sin año, ed. facsímil Ramón Menéndez Pidal (Madrid: Centro de Estudios Históricos, 1914 y Madrid: Consejo Superior de 
Investigaciones Científicas, 1945).

Candau Chacón, M. ${ }^{a}$ Luisa, "El amor conyugal, el buen amor. Joan Estevan y sus "Avisos de casados"', Studia Historica. Historia Moderna 25 (2003): 311-349, https://revistas.usal.es/index.php/Studia Historica/issue/view/381

Carriazo, Juan de Mata, "Amor y moralidad bajo los Reyes Católicos", Revista de Archivos, Bibliotecas y Museos 60 (1954) 53-76.

Castillo, Hernando del, Cancionero general (Valencia: Cristóbal Kofman, 1511), reproducción facsímil Antonio Rodríguez-Moñino (Madrid: Real Academia Española, 1958).

Catalina García, Juan, "El segundo matrimonio del primer marqués de Cenete", en Homenaje a Menéndez. Pelayo en el vigésimo año de su profesorado, ed. Juan Valera, 2 vols. (Madrid: Viuda e Hijos de M. Tello, 1899), II, 665-681.

Cátedra, Pedro, Amor y pedagogía en la Edad Media (Salamanca: Universidad de Salamanca, 1989).

Dadson, Trevor, Diego de Silva y Mendoza. Poeta y político en la corte de Felipe III (Granada, Universidad, 2011).

Duby, Georges, Le chevalier, la femme et le prêtre: le mariage dans la France féodale (París: France Loisirs, 1981).

Elias, Norbert, Elproceso de la civilización: investigaciones sociogenéticas y psicogenéticas (México: Fondo de Cultura Económica, 2015, edición electrónica).

Ermengaut, Matfre, Le breviari d'amor, ed. Peter T. Ricketts (Leiden: Brill, 1976).

Fernández de Oviedo, Gonzalo, Batallas y quincuagenas, ed. Juan Bautista Avalle Arce (Salamanca: Diputación, 1989).

—, Batallas y quincuagenas, ed. Juan Pérez de Tudela y Bueso (Madrid: Real Academia de la Historia, 1983-2002).

Fernández Valladares, Mercedes, La imprenta en Burgos (1501-1600) 2 vols. (Madrid: Arco Libros, 2005).

Gámez Montalvo, $\mathrm{M}^{\mathrm{a}}$ Francisca, Régimen jurídico de la mujer en la familia castellana medieval (Granada, Comares, 1988).

Gaudemet, Jean, El matrimonio en Occidente (Madrid: Taurus, 1993). 
González Cuenca, Joaquín, Cancionero general de Hernando del Castillo (Madrid: Castalia, 2004).

Layna Serrano, Francisco, Historia de Guadalajara y sus Mendozas en los siglos XV y XVI, 4 vols. (Madrid: Consejo Superior de Investigaciones Científicas, 1942-1943, reedición de Guadalajara: Aache, 1994).

Lazar, Moshe, Amour courtois et "Fin'amors" dans la littérature du XIIè siècle (París: Klincksieck, 1964).

Manrique, Jorge, Poesía, ed. Vicenç Beltran (Madrid-Barcelona: Real Academia Española-Galaxia Gutenberg-Círculo de Lectores, 2013)

Manuel, don Juan, Obras completas, ed. José Manuel Blecua (Madrid: Gredos, 19811983).

Marín Pina, M. a Carmen, "Las cartas de amor caballerescas como modelos epistolares", en La recepción del texto literario. (Coloquio franco-español. Jaca, abril de 1986), ed. Jean-Pierre Étienvre y Leonardo Romero (Zaragoza: Universidad de Zaragoza, 1988), 11-24.

—, "De los géneros y diferencias de las cartas caballerescas", en Páginas de sueños. Estudio sobre los libros de caballerías castellanos (Zaragoza: Institución Fernando el Católico, 2011), 169-218.

Martínez Hernández, Santiago, "El desafío de la Casa de Toledo: Felipe II y el proceso contra don Fadrique de Toledo, IV Duque de Alba (1566-185)", Mediterranea. Ricerche storiche 29 (2013): 473-512.

-, "Cartas de amor y el amor en cartas en tiempo de Felipe II. El epistolario inédito de don Fadrique de Toledo con doña Magdalena de Guzmán, ca. 1565-1566”, Hispanic Research Journal 18, 4 (2017): 283-305, https://doi.org/10.1080/1468 $\underline{2737.2017 .1337873}$

Márquez Villanueva, Francisco, Investigaciones sobre Juan Álvarez Gato. Contribución al conocimiento de la literatura castellana del siglo XV (2. ${ }^{a}$ ed., Madrid: Real Academia Española, 1974).

Masdovelles, Joan Berenguer de, Cançoner dels Masdovelles (Manuscrit 11 de la Biblioteca de Catalunya), ed. Ramon Aramon i Serra (Barcelona: Institut d'Estudis CatalansBiblioteca de Catalunya, 1938).

Memorial del pleito entre D. Íñgo López de Mendoza y Fonseca, marqués del Cenete, duque del 
Infantado, y D. Rodrigo Mesía y Fonseca, marqués de la Guardia, y D. Antonio de Toledo y Fonseca, Madrid, Real Academia de la Historia, Colección Salazar, V-60.

Menéndez Pelayo, Marcelino, Antología de poetas líricos castellanos. Poesía de la Edad Media (Santander: Consejo Superior de Investigaciones Científicas, 1945).

Milà, Lluís del, El cortesano, ed. Josep Lluís Escartí, Vicent Josep Escartí i Antoni Tordera (València: Biblioteca Valenciana-Universitat-Ajuntament de València, 2001).

Morant, Isabel, Discursos de la vida buena. Matrimonio, mujer y sexualidad en la literatura bumanista (Madrid: Cátedra, 2002).

Morant, Isabel, y Mónica Bolufer, Amor, matrimonio y familia (Madrid: Síntesis, 2000).

Muir, Kenneth, "Unpublished Poems in the Devonshire Ms.", Proceedings of the Leeds Philosopbical Society (Literary and Historical Section) 6 (1947): 253-82.

Nelli, René, L'érotique des troubadours (Toulouse: Édouard Privat, 1963).

Perea Rodríguez, Óscar, Estudio biográfico sobre los poetas del "Cancionero general" (Madrid: Consejo Superior de Investigaciones Científicas, 2007).

Portugal, Francisco de, Arte de galantería, ed. José Adriano de Freitas Carvalho (Oporto: Centro Inter-Universitário de História da Espiritualidade, 2012).

Primera parte dela Silua de varios romances [...], ed. Vicenç Beltran, (México: Frente de Afirmación Hispanista, 2016).

Pulgar, Fernando del, Letras, ed. Paola Elia (Pisa: Giardini, 1982).

Quirós, Poesie, ed. Massimiliano Andreoli (Nápoles: Liguori Editore, 2005).

Ravasini, Ines, "Poesía y vida de corte: los sonetos en El Cortesano de Luis Milán", Revista de Poética Medieval 28 (2014) 335-357, https://doi.org/10.37536/RPM. 2014.28.0.53210.

Real Academia Española y Asociación de Academias de la Lengua Española, Diccionario de la lengua española, https://dle.rae.es//fecha de consulta: 5/5/2019].

Ricketts, Peter T., Les poésies de Guilhem de Montanhagol, troubadour provençal du XIIIe siècle (Toronto: Pontifical Institute of Mediaeval Studies, 1964).

Rodríguez-Moñino, Antonio, Manual bibliográfico de cancioneros y romanceros del siglo XVI, 
coord. Arthur L.-F. Askins, 4 vols. (Madrid: Castalia, 1973), II.

—, Nuevo Diccionario bibliográfico de pliegos sueltos poéticos. Siglo XVI, ed. Arthur L.-F. Askins y Víctor Infantes (Madrid: Castalia-Editora Regional de Extremadura, 1997).

Rucquoi, Adeline, Aimer dans l'Espagne Médiévale. Plaisir licites et illicites (París: Les Belles Lettres, 2008).

Silva y Mendoza, Diego de, conde de Salinas, Obra completa. 1. Poesía desconocida, ed. Trevor Dadson (Madrid: Real Academia Española-Centro para la Edición de los Clásicos Españoles, 2016).

Singer, Irving, La naturaleza del amor. 1. De Platón a Lutero. 2. Cortesano y romántico. 3. El mundo moderno (México: Siglo XXI Editores, 1992).

Usunáriz, Jesús M. a, "El matrimonio como ejercicio de libertad en la España del siglo de oro", en El matrimonio en Europa y el mundo hispánico: siglos XVI y XVII, ed. Jesús M. ${ }^{a}$ Usunáriz e Ignacio Arellano (Madrid: Visor, 2005), 167-186.

-, "Palabras de amor en el mundo hispánico: emociones y sentimientos en la correspondencia privada del Siglo de Oro", en Por seso e por maestría. Homenaje a la profesora Carmen Saralegui, ed. Concepción Martínez Pasamar y Cristina Tabernero Sala (Pamplona: Eunsa, 2012), 555-597.

—, "Sentimientos e historia. La correspondencia amorosa en los siglos XVI-XVIII", en Cinco siglos de cartas. Historia y prácticas epistolares en las épocas moderna y contemporánea, ed. Antonio Castillo Gómez y Verónica Sierra Blas (Huelva: Universidad de Huelva, 2014), 251-274.

-, "Marriage and Love in Sixteenth- and Seventeenth-Century Spain", en Marriage in Europe. 1400-1800, ed. Silvana Seidel Menchi (Toronto-Buffalo-Londres: University of Toronto, 2016), 201-224.

Vélez de Guevara, Luis, Reinar después de morir, ed. Giuseppe Carlo Rossi (Nápoles: Pironte e Figli, 1961).

Vaquero Serrano, M. ${ }^{a}$ Carmen, Garcilaso, principe de poetas. Una biografía (Madrid: Marcial Pons, 2013).

Walde Moheno, Lillian van der, Amor e ilegalidad. "Grisel y Mirabella" de Juan de Flores (México: Universidad Autónoma Nacional de México-El Colegio de México, 1996).

Whinnom, Keith, "Towards the Interpretation and Appreciation of the Canciones of 
the Cancionero general of 1511", en Medieval and Renaissance Spanish Literature. Selected Essays, ed. Alan Deyermond, William F. Hunter y Joseph Snow (Exeter: University of Exeter Press-Journal of Hispanic Philology, 1994), 114-132.

Zurita, Jerónimo, Historia del rey don Hernando el Católico: de las empresas y ligas de Italia, ed. Ángel Canellas López, Magdalena Canellas Allos y Antonio J. López Gutiérrez (Zaragoza: Diputación General de Aragón, 1989-1996).

Recibido: 26 de enero de 2021 Aprobado: 29 de marzo de 2021 